\title{
Defining Why the Re-excision Rate Dropped
}

\author{
Anees B. Chagpar, MD, MSc, MPH, MA, MBA, FRCSC, FACS \\ Department of Surgery, Yale University, New Haven, CT
}

In this issue of Annals of Surgical Oncology, Havel et al. ${ }^{1}$ report the first meta-analysis documenting the presumed impact of the SSO-ASTRO margin guideline on rates of re-excision. The work, encompassing two national studies, as well as five institutional ones, documents what would be the logical outcome-that when one changes the definition of what is a positive margin requiring re-excision to become more narrow, the re-excision rates decline..$^{2-8}$

Problematic, however, is that they could not actually document why re-excisions decreased. Was it really the change in definition? Or are surgeons simply becoming better at obtaining negative margins? Attribution of causation, without evidence of the same, is an issue. Nonetheless, it is likely that the margin definition did have an impact. In 2014, Landercasper et al. ${ }^{9}$ found in a study of 1451 patients who required re-excision, that $41.5 \%$ were done for margins $<2 \mathrm{~mm}$, but with no tumor at ink. By 2015, deSnyder et al., ${ }^{10}$ in a survey of 777 members of the American Society of Breast Surgeons, found that $92 \%$ were familiar with the newly published guideline and only $1.3 \%$ reported that they would "always or most of the time" reexcise a tumor that was within $2 \mathrm{~mm}$ of (but not at) the inked surface. Still, they found some variation; clinical judgement often was used to determine optimal margin width given various clinicopathologic factors.

Havel et al. acknowledge this, and the fact that other factors, including improved surgical technique may contribute to the $35 \%$ reduction in re-excision rate noted in their analysis. Indeed, over this period of time, randomized, controlled trials of resection of cavity shave margins were being performed, which demonstrated a $50 \%$ reduction in

(C) Society of Surgical Oncology 2019

First Received: 28 January 2019; Published Online: 24 February 2019

A. B. Chagpar, MD, MSc, MPH, MA, MBA, FRCSC, FACS

e-mail: anees.chagpar@yale.edu re-excision rate. ${ }^{11,12}$ This, however, was independent of the definition change that occurred; i.e., in the SHAVE trial, the definition of a positive margin for invasive disease was "no tumor at ink." Still, the technique found a significant reduction in positive margin and re-excision rate. ${ }^{11}$ Hence, the amount to which various technical improvements in surgical procedure versus the definition change had an impact on the overall reduction in re-excision rates demonstrated in this meta-analysis remains unclear.

Regardless of why the re-excision rate decreased, and the relative impact of various factors, most celebrate this trend. Our focus on margin positivity and the need to reduce this, however, is grounded in the notion that positive margins leads to local recurrence. While recent years have seen a plethora of studies and technologies emerging to help in this pursuit, we are at the same time questioning the very premise on which this is based. Authors have questioned whether all positive margins need to be re-excised-whether only those with extensive (rather than focal) involvement should matter, and whether anterior margins should "count." ${ }^{13,14}$ Indeed, in an era with nearly ubiquitous adjuvant systemic and radiation therapy, one may question the impact of a positive margin, particularly given that $\sim 50 \%$ of these patients will have no further disease at re-excision. Given that $12-14 \%$ of patients with negative margins have occult disease, which does not seem to impact survival, some have argued that our fervor in the chase for the almighty negative margin may be misplaced. At the end of the day, we must ask ourselves the question: do margins matter? Insofar as the answer to that question (at least for the moment) is yes, we must hold to the concept that the definition of an actionable margin is critical, and this, along with techniques that try to minimize positive margins, have played a key role in reducing the need for unnecessary re-excisions. 


\section{REFERENCES}

1. Havel L, Naik H, Ramirez L, Morrow M, Landercaspper J. Impact of the SSO-ASTRO margin guideline on rates of re-excision after lumpectomy for breast cancer: a meta-analysis. Ann Surg Oncol. 2019. https://doi.org/10.1245/s10434-019-07247-5.

2. Schulman AM, Mirrielees JA, Leverson G, Landercasper J, Greenberg C, Wilke LG. Reexcision surgery for breast cancer: an analysis of the American Society of Breast Surgeons (ASBrS) Mastery $^{\text {SM }}$ Database following the SSO-ASTRO "no ink on tumor" guidelines. Ann Surg Oncol. 2017;24(1):52-8.

3. Morrow M, Abrahamse P, Hofer TP, et al. Trends in reoperation after initial lumpectomy for breast cancer: addressing overtreatment in surgical management. JAMA Oncol. 2017;3(10):1352-7.

4. Rosenberger LH, Mamtani A, Fuzesi S, et al. Early adoption of the SSO-ASTRO consensus guidelines on margins for breastconserving surgery with whole-breast irradiation in stage I and II invasive breast cancer: initial experience from Memorial Sloan Kettering Cancer Center. Ann Surg Oncol. 2016;23(10):3239-46.

5. Patten CR, Walsh K, Sarantou T, et al. Changes in margin reexcision rates: experience incorporating the "no ink on tumor" guideline into practice. J Surg Oncol. 2017;116(8):1040-5.

6. Bhutiani N, Mercer MK, Bachman KC, et al. Evaluating the effect of margin consensus guideline publication on operative patterns and financial impact of breast cancer operation. $J A m$ Coll Surg. 2018;227(1):6-11.

7. Chung A, Gangi A, Amersi F, Bose S, Zhang X, Giuliano A. Impact of consensus guidelines by the Society of Surgical Oncology and the American Society for Radiation Oncology on margins for breast-conserving surgery in stages 1 and 2 invasive breast cancer. Ann Surg Oncol. 2015;22(Suppl 3):S422-7.
8. Heelan Gladden AA, Sams S, Gleisner A, et al. Re-excision rates after breast conserving surgery following the 2014 SSO-ASTRO guidelines. Am J Surg. 2017;214(6):1104-9.

9. Landercasper J, Whitacre E, Degnim AC, Al-Hamadani M. Reasons for re-excision after lumpectomy for breast cancer: insight from the American Society of Breast Surgeons Mastery ${ }^{\text {SM }}$ database. Ann Surg Oncol. 2014;21(10):3185-91.

10. DeSnyder SM, Hunt KK, Smith BD, Moran MS, Klimberg S, Lucci A. Assessment of practice patterns following publication of the SSO-ASTRO consensus guideline on margins for breastconserving therapy in stage I and II invasive breast cancer. Ann Surg Oncol. 2015;22(10):3250-6.

11. Chagpar AB, Killelea BK, Tsangaris TN, et al. A randomized, controlled trial of cavity shave margins in breast cancer. $N$ Engl $J$ Med. 2015;373(6):503-10.

12. Jones V, Linebarger J, Perez S, et al. Excising additional margins at initial breast-conserving surgery (BCS) reduces the need for reexcision in a predominantly African American population: a report of a randomized prospective study in a public hospital. Ann Surg Oncol. 2016;23(2):456-64.

13. Park S, Park HS, Kim SI, Koo JS, Park BW, Lee KS. The impact of a focally positive resection margin on the local control in patients treated with breast-conserving therapy. Jpn J Clin Oncol. 2011;41(5):600-8.

14. Mullen R, Macaskill EJ, Khalil A, et al. Involved anterior margins after breast conserving surgery: Is re-excision required? Eur J Surg Oncol. 2012;38(4):302-6.

Publisher's Note Springer Nature remains neutral with regard to jurisdictional claims in published maps and institutional affiliations. 